\title{
Practice Recommendations for Diagnosis and Treatment of the Most Common Forms of Secondary Hypertension
}

\author{
Gian Paolo Rossi ${ }^{1}$ (1) - Valeria Bisogni ${ }^{1} \cdot$ Giacomo Rossitto $^{1}$ - Giuseppe Maiolino ${ }^{1} \cdot$ Maurizio Cesari $^{1} \cdot$ Rui Zhu $^{1}$. \\ Teresa Maria Seccia ${ }^{1}$
}

Received: 20 July 2020 / Accepted: 10 October 2020 / Published online: 7 November 2020

(c) The Author(s) 2020

\begin{abstract}
The vast majority of hypertensive patients are never sought for a cause of their high blood pressure, i.e. for a 'secondary' form of arterial hypertension. This under detection explains why only a tiny percentage of hypertensive patients are ultimately diagnosed with a secondary form of arterial hypertension. The prevalence of these forms is, therefore, markedly underestimated, although, they can involve as many as one-third of the cases among referred patients and up to half of those with difficult to treat hypertension. The early detection of a secondary form is crucial, because if diagnosed in a timely manner, these forms can be cured at long-term, and even when cure cannot be achieved, their diagnosis provides a better control of high blood pressure, and allows prevention of hypertension-mediated organ damage, and related cardiovascular complications. Enormous progress has been made in the understanding, diagnostic work-up, and management of secondary hypertension in the last decades. The aim of this minireview is, therefore, to provide updated concise information on the screening, diagnosis, and management of the most common forms, including primary aldosteronism, renovascular hypertension, pheochromocytoma and paraganglioma, Cushing's syndrome, and obstructive sleep apnea.
\end{abstract}

Keywords Primary aldosteronism · Renovascular hypertension $\cdot$ Pheochromocytoma/paraganglioma $\cdot$ Cushing's syndrome $\cdot$ Obstructive sleep apnea

\section{Introduction}

By definition 'secondary' hypertension ( $\mathrm{SH}$ ) comprises those forms of arterial hypertension (HT) that are due to an identified cause and, therefore, can be resolved by removing the underlying cause.

The European Societies of Cardiology and Hypertension $(\mathrm{ESC} / \mathrm{ESH})$ guidelines suggest that the screening for SH should be restricted to patients with certain features, such as younger age (i.e. $<40$ years), acute worsening of HT in patients with previously documented chronically stable normotension, severe (grade 3) or drug-resistant

Gian Paolo Rossi and Valeria Bisogni have contributed equally to this manuscript.

Gian Paolo Rossi

gianpaolo.rossi@unipd.it

1 Clinica dell'Ipertensione Arteriosa, Department of Medicine-DIMED, University of Padua, University Hospital, via Giustiniani, 2, 35126 Padova, Italy
HT, presence of extensive hypertension-mediated organ damage (HMOD) [1]. However, accumulating experiences in specialized tertiary referral centers have provided compelling evidence that if $\mathrm{SH}$ is systematically sought for, its prevalence is much higher [2], involving a proportion of the hypertensive patients that ranges from about $35 \%$ in general to higher rates in those with drug-resistant HT [3]. For example, amongst those with primary aldosteronism who were referred for adrenal vein sampling (AVS) in the Adrenal Vein sampling International Study (AVIS)-2, 20-50\% had resistant hypertension depending on the criteria used to define this condition [4]. Even though specialized centers receive a selected cohort of patients, these figures indicate that the diagnosis of $\mathrm{SH}$ is probably missed in the majority of the patients. This is a disastrous situation, not only because it implies missing the opportunity of long-term cure and/or a better control of high blood pressure (BP), but also because identification of the cause and the underlying pathophysiological mechanisms allows a more targeted and effective pharmacological treatment, and, therefore, prevention of HMOD and cardiovascular (CV) events [5]. Given 
the unprecedented progress made in the last decades in the understanding, screening, work-up, and management of SH, the purpose of this mini-review is to furnish concise updated information on the diagnosis and treatment of the most common forms of SH, which are summarized in Table 1. For in depth information, the readers are referred to recent comprehensive reviews $[6,7]$.

\section{Primary Aldosteronism}

Keynote PA is the most common curable form of HT. Its prior probability is higher in certain categories of patients, which makes its detection obligatory in such categories. However, several experts call for broader screening strategies with the aim to surgically cure or medically treat PA patients, thus avoiding or reverse HMOD and CV complications.

Table 1 Causes of secondary hypertension

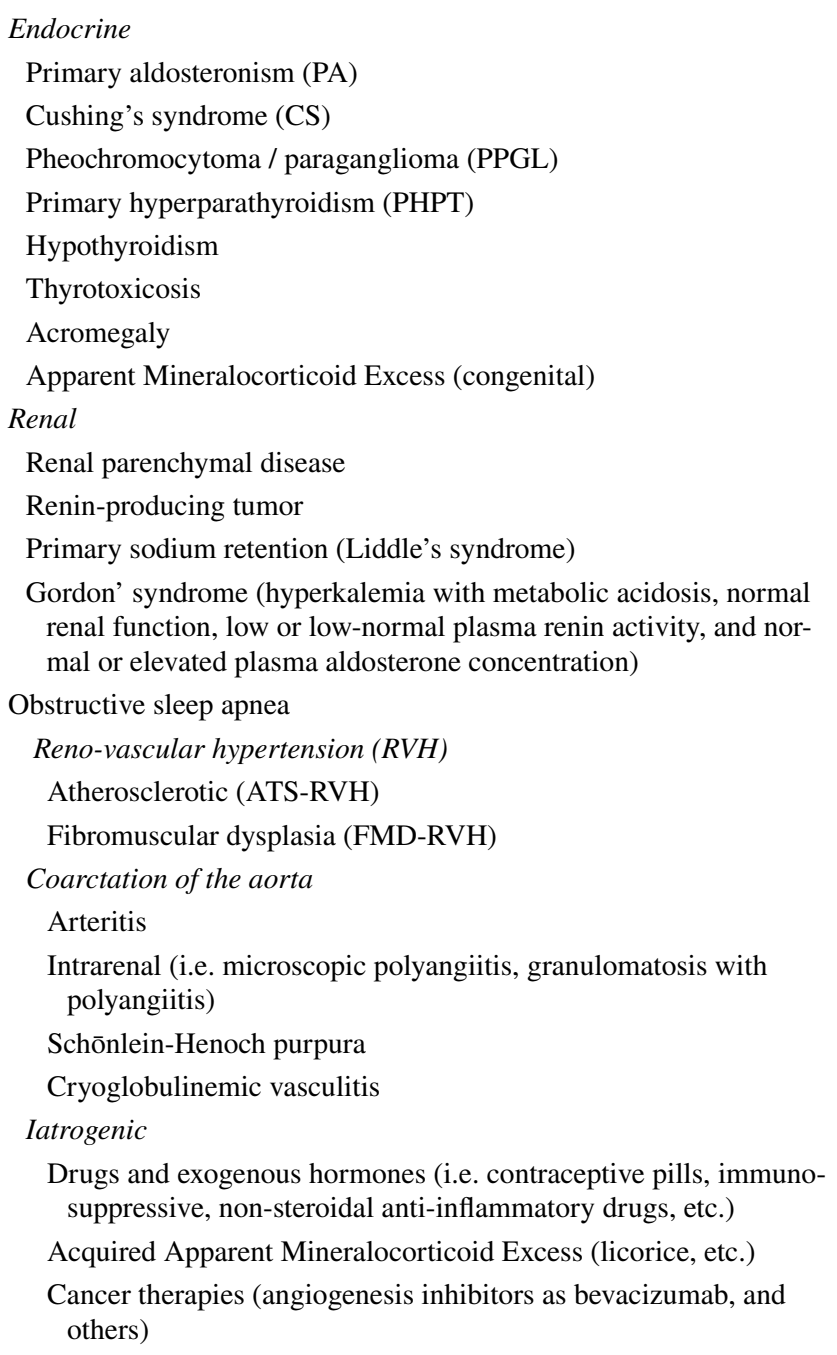

Primary aldosteronism (PA) is by far the most common curable form of HT and is associated with an excess rate of HMOD and CV complications as compared to primary essential HT with a similar degree of BP elevation $[8,9]$. Its prevalence ranges from $6 \%$ in unselected hypertensive patients [10] to $11.2 \%$ in those referred to specialized centers [11], and to more $20 \%$ in the patients with drug-resistant HT $[12,13]$.

\subsection{Screening and Diagnostic Tests}

Table 2 reports the main clinical features of PA. When the PA patients were systematically subtyped by using adrenal vein sampling (AVS), about two-thirds of them were found to have a unilateral form of PA, mainly an aldosteroneproducing adenoma (APA) or, much more rarely, unilateral adrenal hyperplasia, while a bilateral form (also known as idiopathic hyperaldosteronism) was diagnosed in the remaining third [11]. The main feature of patients with bilateral PA is multiple aldosterone-producing cell clusters (APCCs) or micro-aldosterone-producing adenomas, rather than bilateral adrenal hyperplasia (BAH) [14], which seems to be the more common form when AVS is not systematically exploited or it is interpreted with cutoffs for selectivity and lateralization that are too tight [15]. Much rarer are unilateral aldosteroneproducing carcinomas [16], and the familial forms (FH) due to germline mutations, which cause BAH [17] and include several types (e.g. FH-I—also known as 'glucocorticoidremediable aldosteronism', II, III, and IV).

Figure 1 shows a simplified algorithm for the initial workup of PA [9], which performed extremely well at our center. Briefly, the diagnosis of PA entails demonstration of low or undetectable renin levels and inappropriately high secretion of aldosterone. Considering this, in 1982 Hiramatsu et al. proposed the aldosterone : renin ratio (ARR) [18], which can now be easily calculated using the freely downloadable ARR App (available for Android and iPhone) [19]. To effectively use the ARR one should, however, be aware that its values are influenced by many drugs and conditions (Table 3) [9, 20]. Thus, the usual recommendation is to switch antihypertensive therapy to doxazosin and/or a long-acting calcium-channel blocker, and also to keep the patients resting quietly (supine or sitting) for $60 \mathrm{~min}$ before collecting blood samples [9]. However, a major advancement in this field with profound implications for clinical practice has been the discovery that the mineralocorticoid receptor antagonists (MRAs), which for decades were forbidden during the screening, can be prescribed during the screening of PA [21], and also when PA patients undergo subtype differentiation because they did not cause false negative ARR values during the screening, neither they precluded the diagnosis of unilateral PA by AVS [22-24]. This novel evidence is of utmost practical importance particularly in the patients 
Table 2 Clinical characteristics suggestive of primary aldosteronism

Sustained BP $>150 / 100 \mathrm{mmHg}$ on each of 3 measurements obtained on different days

Hypertension (BP > 140/90 $\mathrm{mmHg}$ ) resistant to 3 conventional antihypertensive drugs (including a diuretic)

Spontaneous or diuretic-induced hypokalemia

Hypertension and adrenal incidentaloma

Obstructive sleep apnea

Family history of primary aldosteronism and/or early-onset hypertension or cerebrovascular accident at a young age ( $<40$ years)

Atrial fibrillation not explained by other causes (i.e. valvular disease)

HMOD (i.e. LVH, diastolic dysfunction, microalbuminuria, CKD) in excess of what expect based on BP values

$B P$ blood pressure, $H M O D$ hypertension-mediated organ damage, $L V H$ left ventricular hypertrophy, $C K D$ chronic kidney disease

with severe hypokalemia and/or poor control of BP values, because the MRAs are the most effective agents to control $\mathrm{BP}$ and hypokalemia in PA patients.

The use of confirmatory tests, such as the oral sodium loading test, the saline infusion test, the captopril challenge test, and the fludrocortisone plus salt loading test, remains controversial. They are based on the unproven premise that aldosterone secretion would be completely independent of renin and angiotensin II. Moreover, studies that supported their use did not comply with the Standards for Reporting of Diagnostic Accuracy (STARD) requirement for validation for diagnostic tests [25]. Furthermore, the largest study that examined the captopril test and fulfilled these requirementsthe AQUARR Study - failed to show any diagnostic gain of this confirmatory test over a carefully done ARR [26]. Thus, if the screening is properly performed and shows an ARR consistently elevated, i.e. a florid PA phenotype (identified by a high aldosterone $>15 \mathrm{ng} / \mathrm{dL}$, a DRC $\leq 2 \mathrm{mIU} / \mathrm{L}$, with or without low potassium levels), they are useless, and patients can proceed to subtyping if they seek for surgery [27, 28].

\subsection{Treatment}

Unilateral laparoscopic adrenalectomy is the best treatment that can be offered to PA patients with proven unilateral disease. This means that patients should be referred for AVS to be performed by an expert team in a specialized tertiary center before considering surgery. MRAs, such as spironolactone, canrenone potassium, potassium canrenoate, eplerenone, alone or in combination with other antihypertensive drugs, are recommended for those patients with BAH or not suitable for surgery. MRAs are also indicated before adrenalectomy to control BP values and serum potassium levels $[9,27]$. In both surgically and medically treated PA, follow-up is necessary to verify the 'cure' of PA and the effectiveness of treatment $[29,30]$.

A more in-depth discussion of the diagnostic work-up and treatment is available in the 2020 Italian Society of Arterial Hypertension (SIIA) practical guidelines [28].

\section{Renovascular Hypertension (RVH)}

\begin{tabular}{ll}
\hline Keynote & The main causes of renal artery \\
& stenosis in RVH patients are \\
& fibromuscular dysplasia (FMD) \\
and atherosclerosis (ATS). FMD & is most frequent in young-to- \\
middle aged women, while & ATS prevails in adult men with \\
multiple risk factors. \\
\hline
\end{tabular}

Renovascular hypertension (RVH) defines a condition where renal artery occlusion or stenosis decreases renal perfusion pressure to levels that activates the renin-angiotensin-aldosterone system (RAAS), thereby raising BP. Its major causes are fibromuscular dysplasia (FMD) and atherosclerosis, which usually involve different cohorts of patients. FMD affects especially children and young-tomiddle aged women [31], and is a systemic arterial disease. It causes RVH (FMD-RVH) when it involves the renal artery. Atherosclerotic renovascular hypertension (ATS-RVH) is the most common form in older adults, predominantly men, with multiple risk factors. Its prevalence in the general population of patients with HT ranges between 1 and $8 \%$, depending on the selection of the population, but can be as high as $25-35 \%$ in patients with signs of multisite atherosclerosis [7].

RAAS activation occurs when the narrowing of the renal artery lumen in one or both renal arteries attains a certain threshold, usually estimated $>75 \%$, or can be presumed even at a lower degree of stenosis if there is poststenotic dilatation. The increased renin synthesis aims at maintaining glomerular filtration rate (GFR) through a prominent constriction of the post-glomerular arterioles and via the elevation of systemic BP. In the majority of the patients, however, at the time of diagnosis, the activation of the RAAS is no longer detectable for multiple reasons, as discussed elsewhere [32]. 


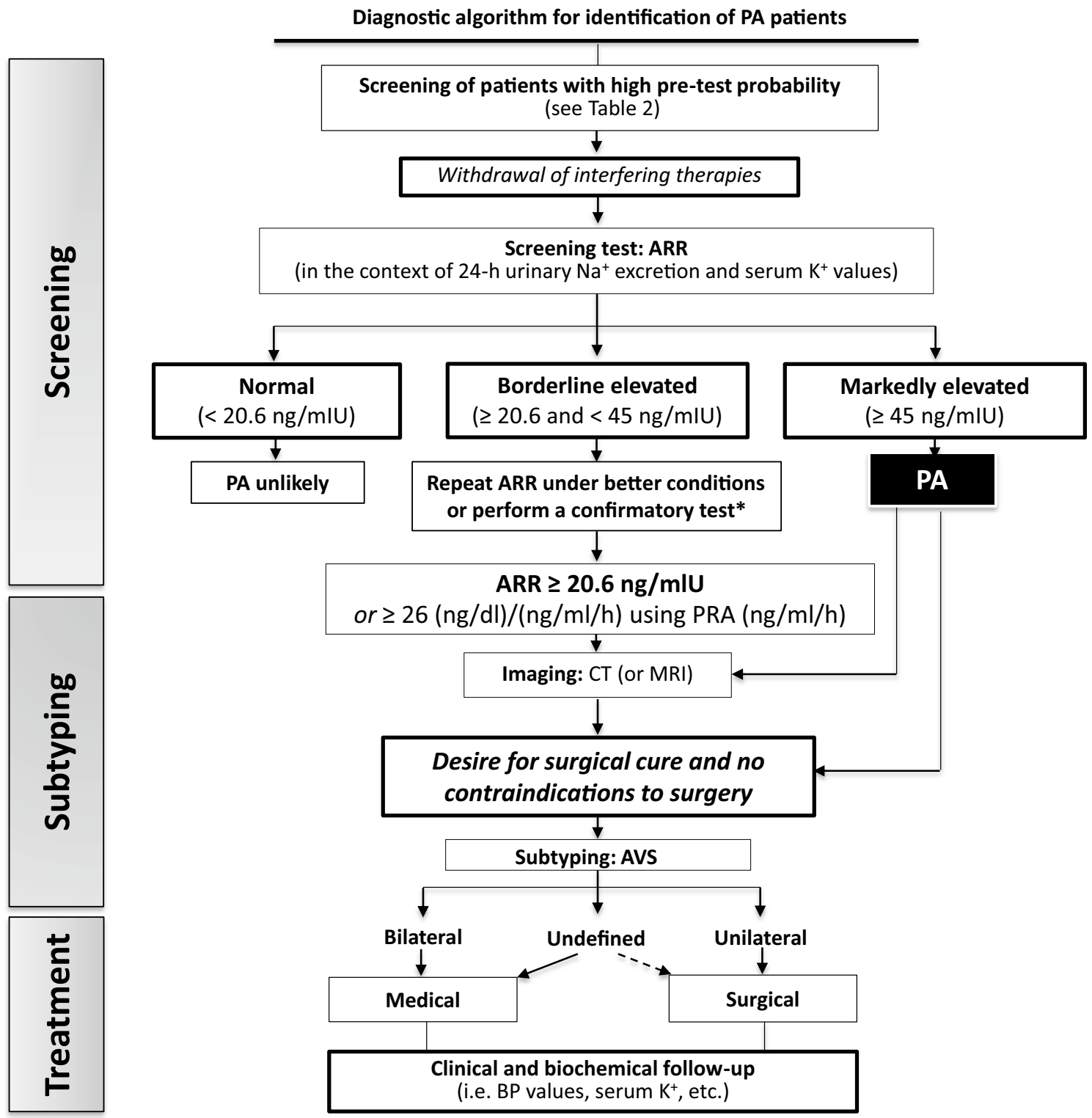

Fig. 1 Simplified algorithm for the work-up for primary aldosteronism. Please note the pivotal role of adrenal vein sampling (AVS) for patient's assignment to surgery or medical treatment. In case of uncertain AVS results or unsuccessful AVS, the indication to unilateral adrenalectomy can be justified by in case of drug-resistant hypertension and/or unbearable side effects with the antihypertensive treatment. *Confirmatory tests are not explained in this simplified algorithm because their accuracy and diagnostic gain over a

In fact, it has to be reckoned that stenosis of the renal arteries may be hemodynamically insignificant and can result from accelerated atherosclerosis in patients with primary HT. Hence, confirming the diagnosis of RVH is a challenging undertaking, as this can only be made retrospectively if revascularization results in the cure or improvement of HT [5]. well-performed baseline ARR has not been proven in studies that fulfilled the Standards for Reporting of Diagnostic Accuracy (STARD) requirements [25]. Moreover, in the largest and only study that followed these requirements, the captopril test was not shown to provide any diagnostic gain over the baseline ARR [26]. $P A$ primary aldosteronism, $A R R$ aldosterone: renin ratio, $P R A$ plasma renin activity, $K^{+}$ potassium, $\mathrm{Na}^{+}$sodium, $\mathrm{CT}$ computed tomography, MRI magnetic resonance imaging, $A V S$ adrenal vein sampling, $B P$ blood pressure

\subsection{Screening and Diagnostic Tests}

For the reason just mentioned, the work-up of RVH, which has to be undertaken in a clinically selected high-risk population (Table 4 and Fig. 2), cannot rely solely on the biochemical assessment, i.e. measurement of serum potassium levels, 24-h urinary sodium and potassium excretion, 
Table 3 Drugs and conditions that affect aldosterone, renin, and aldosterone:renin ratio Adapted from Rossi GP. Primary Aldosteronism: JACC State-of-the-Art Review. J Am Coll Cardiol. 2019;74:2799-811 [9]

\begin{tabular}{|c|c|c|c|c|c|}
\hline Factor & PAC & Renin & ARR & FP rate & FN rate \\
\hline \multicolumn{6}{|l|}{ Medications } \\
\hline$\beta$-Blockers & $\downarrow$ & $\downarrow \downarrow$ & $\uparrow$ & $\uparrow \uparrow$ & $\downarrow$ \\
\hline $\begin{array}{l}\text { Central } \alpha-2 \text { adrenergic } \\
\text { receptor agonists }^{\mathrm{a}}\end{array}$ & $\downarrow$ & $\downarrow \downarrow$ & $\uparrow$ & $\uparrow$ & $\downarrow$ \\
\hline NSAIDs & $\downarrow$ & $\downarrow \downarrow$ & $\uparrow$ & $\uparrow$ & $\downarrow$ \\
\hline $\mathrm{K}^{+}$-losing diuretic agents & $\uparrow$ & $\uparrow \uparrow$ & $\downarrow$ & $\downarrow$ & $\uparrow$ \\
\hline $\mathrm{K}^{+}$-sparing diuretic agents & $\uparrow$ & $\uparrow \uparrow$ & $\downarrow$ & $\downarrow$ & $\uparrow$ \\
\hline ACE inhibitors & $\downarrow$ & $\uparrow \uparrow$ & $\downarrow$ & $\downarrow$ & $\uparrow$ \\
\hline ARBs & $\downarrow$ & $\uparrow \uparrow$ & $\downarrow$ & $\downarrow$ & $\uparrow$ \\
\hline Long-acting CCBs & $\rightarrow \downarrow$ & $\rightarrow$ & $\downarrow$ & $\rightarrow \downarrow$ & $\rightarrow \uparrow$ \\
\hline \multicolumn{6}{|l|}{ Potassium status } \\
\hline Hypokalemia & $\downarrow$ & $\rightarrow \uparrow$ & $\downarrow$ & $\downarrow$ & $\uparrow$ \\
\hline Potassium loading & $\uparrow$ & $\rightarrow \uparrow$ & $\uparrow$ & $\uparrow$ & $\downarrow$ \\
\hline \multicolumn{6}{|l|}{ Sodium status } \\
\hline Sodium depletion & $\uparrow$ & $\uparrow \uparrow$ & $\downarrow$ & $\downarrow$ & $\uparrow$ \\
\hline Sodium loading & $\downarrow$ & $\downarrow \downarrow$ & $\uparrow$ & $\uparrow$ & $\downarrow$ \\
\hline \multicolumn{6}{|l|}{ Other conditions } \\
\hline Aging & $\downarrow$ & $\downarrow$ & $\uparrow$ & $\uparrow$ & \\
\hline Renal impairment & $\rightarrow$ & $\downarrow$ & $\uparrow$ & $\uparrow$ & $\downarrow$ \\
\hline Pregnancy & $\uparrow$ & $\uparrow \uparrow$ & $\downarrow$ & $\downarrow$ & $\downarrow$ \\
\hline Renovascular & $\uparrow$ & $\uparrow \uparrow$ & $\downarrow$ & $\downarrow$ & $\uparrow$ \\
\hline Malignant & $\uparrow$ & $\uparrow \uparrow$ & $\downarrow$ & $\downarrow$ & $\uparrow$ \\
\hline
\end{tabular}

$P A C$ plasma aldosterone concentration, $A R R$ aldosterone: renin ratio, $A C E$ angiotensin-converting enzyme, $A R B s$ angiotensin II type 1 receptor blockers, NSAIDs non-steroidal anti-inflammatory drugs, $C C B$ s calcium-channel blockers, $F P$ false positive, $F N$ false negative

${ }^{a}$ Except for moxonidine, which has been associated with no significant change in the ARR values limitedly to healthy volunteers in the study of Ahmed et al. [20]

and active renin concentration or plasma renin activity, but should also entail instrumental tests. The latter comprise: (1) Duplex sonography with bilateral assessment of the most relevant indexes, (e.g. renal arterial resistive, pulsatility indexes, acceleration time, peak systolic velocity, renal-aortic ratio) and evaluation of their homogeneity throughout the different thirds of each kidney; (2) computed tomography (CT) or magnetic resonance angiography, and (3) renal catheter-based contrast angiography. The latter can be implemented with a simultaneous, unstimulated translesional pressure gradient (between the distal renal artery and the aorta) measurement that has been suggested for determining the severity and hemodynamic significance of renal artery stenosis. A pressure gradient threshold of $10 \%$ of the mean (aortic) pressure (or a trans-lesional gradient of at least $20 \mathrm{mmHg}$ ) has been proposed to decide whether or not to perform balloon angioplasty (see "Treatment" section below) [33]. While there are no randomized clinical trials supporting the superiority of this approach in terms of outcome, its pitfalls are both theoretical and practical: positioning a catheter through a tight stenosis by itself creates a gradient, which can lead to an overestimation of the stenosis severity. Moreover, in the presence of multiple lesions, as typically in FMD, estimation of pressure gradient can be challenging. Finally, the measurement of the trans-lesional pressure gradient is not widely available, even in centers that perform a substantial number of percutaneous procedures for RVH.

\subsection{Treatment}

The first-choice treatment for FMD-RVH is renal artery angioplasty without stenting. Its effect on BP reduction is greater in younger patients, with 'short history' of HT, and without comorbidities (such as diabetes mellitus or obesity). In patients with ATS-RVH angioplasty should be performed with stenting, and there are compelling indications to undertake such treatment (Table 5). However, it remains controversial if percutaneous transluminal renal angioplasty (PTRA) plus stenting is superior to an aggressive medical treatment in the patients without such compelling indications (Class of Recommendation IIb, Level of Evidence C) (Fig. 2) [33-35]. According to a guideline, renal artery angioplasty would be 'rarely appropriate' in: (1) asymptomatic unilateral hemodynamically significant RAS in a viable kidney; (2) patients with small ( $<7 \mathrm{~cm}$ pole to pole) nonviable kidneys; (3) patients with moderate RAS (50-69\% diameter stenosis) with translesional gradients that fail to achieve the threshold [35].

\section{Pheochromocytoma/Paraganglioma}

\begin{tabular}{|c|c|}
\hline Keynote & $\begin{array}{l}\text { More than } 80 \% \text { of PPGLs patients } \\
\text { have paroxysmal or sustained } \\
\text { high BP. Screening test includes } \\
\text { measurement of urinary metane- } \\
\text { phrines. When the tumor is } \\
\text { detected by imaging, antihyper- } \\
\text { tensive treatment is based on } \\
\alpha 1 \text {-adrenergic receptor blockade } \\
\text { followed by association with } \\
\beta \text {-blockers. }\end{array}$ \\
\hline
\end{tabular}

About $80-85 \%$ of chromaffin-cell tumors are pheochromocytomas (PHEO), and 15-20\% are paragangliomas (PGL). Owing to their common embryologic origin and clinical similarities, they are usually jointly defined as pheochromocytomas and paragangliomas, in short PPGLs. 
Table 4 Clinical findings suggestive of renovascular hypertension (RVH) according to the etiology

\section{FMD-RVH}

Early onset of HT ( $<30$ years old), especially in women

Unilateral small kidney without a causative urological abnormality

Abdominal bruit in the absence of atherosclerotic disease or risk factors for atherosclerosis

Suspected renal artery dissection/infarction

Presence of FMD in at least 1 other vascular territory

History of stroke, headaches, neck pain, and a pulsatile ringing or swooshing sound in the ears when carotid and/or vertebral arteries is involved

History of ACS caused by spontaneous coronary artery dissection

Weight loss, abdominal pain and ischemia, in case of abdominal artery involvement

Typical symptoms and signs of peripheral artery diseases

Shared by the two conditions

Accelerated, or malignant or grade 3 (> 180/110 mmHg) HT

Drug-resistant hypertension (blood pressure target not achieved despite 3 drug-therapy at optimal doses including a diuretic)

Development of new azotemia or worsening renal function after administration of ACE-inhibitors or ARBs

Unexplained atrophic kidney or size discrepancy between kidneys of greater than $1.5 \mathrm{~cm}$

Sudden, unexplained pulmonary edema

Multi-vessel coronary artery disease

Unexplained congestive heart failure

Refractory angina

FMD fibromuscular dysplasia, ATS atherosclerotic, $H T$ hypertension, $A C S$ acute coronary syndrome, $R A S$ renal artery stenosis, $A C E$ angiotensin converting enzyme, $A R B s$ angiotensin II receptor blockers

Fig. 2 Diagnostic algorithm for identification and treat renovascular hypertension $(\mathrm{RVH})$. As no single test is sensitive and specific enough to detect and ruled out RVH, a comprehensive assessment based on biochemical $\left(\downarrow \mathrm{K}^{+}, \uparrow\right.$ renin, $\uparrow$ plasma aldosterone concentration) and instrumental tests (Duplex sonography and renal post-captopril scintigraphy) is necessary. Imaging by angioCT or angio-MR plays a key role to assess the localization of stenosis and multivessel involvement, and to plan revascularization, by angioplasty in FMD-RVH and angioplasty + stenting in case of ATS-RVH. $R V H$ renovascular hypertension, $F M D$ fibromuscular dysplasia, $C T$ computed tomography, $M R$ magnetic resonance, PTRA percutaneous transluminal renal angioplasty, $B P$ blood pressure

\section{ATS-RAS}

Severe HT $>55$ years old

Most frequent in older people, smokers, obese and diabetic

History of generalized atherosclerosis (coronary artery disease, peripheral vascular disease, etc.)

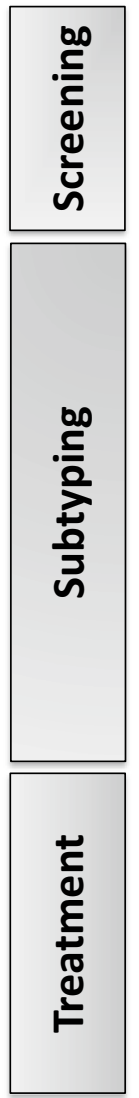

Diagnostic algorithm for identification of RVH

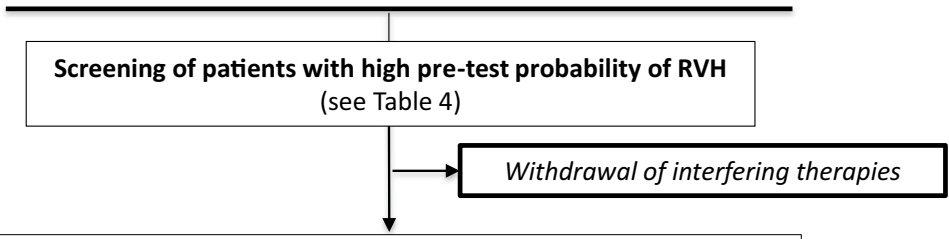

Comprehensive Biochemical and Instrumental assessment

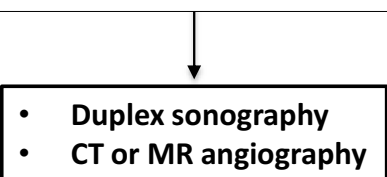

- CT or MR angiography

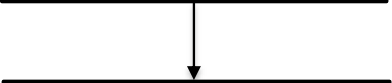

Catheter angiography

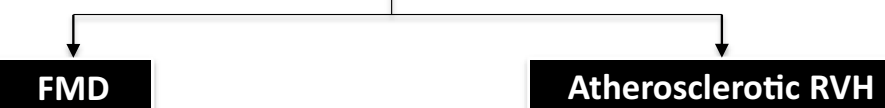

Primary HT with associated renovascular disease
Atherosclerotic RVH

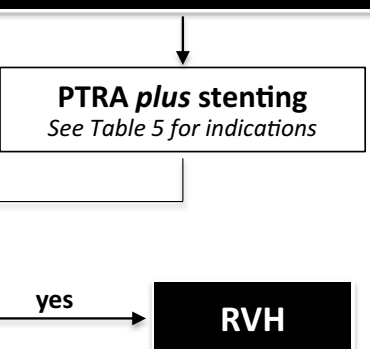


Table 5 ACC/AHA recommendations to perform angioplasty and stent in ATS-RVH Adapted from Hirsch AT, et al. ACC/AHA 2005 Guidelines for the Management of Patients With Peripheral Arterial Disease (Lower Extremity, Renal, Mesenteric, and Abdominal Aor- tic): A Collaborative Report from the American Association for Vascular Surgery/Society for Vascular Surgery. Soc. J Am Coll Cardiol. 2006;47:1239-312 [33]
Indication

Class of recommendation/level of evidence

An asymptomatic bilateral or viable kidney with a hemodynamically significant RAS

$\mathrm{IIb} / \mathrm{C}$

Patients with hemodynamically significant RAS and accelerated HT, resistant HT, malignant HT, HT with an unexplained IIa/C unilateral small kidney, and HT with intolerance to medication

RAS and progressive chronic kidney disease with bilateral RAS or a RAS to a solitary functioning kidney

$\mathrm{IIa} / \mathrm{B}$

Patients with RAS and chronic renal insufficiency with unilateral RAS

$\mathrm{IIb} / \mathrm{C}$

Patients with hemodynamically significant RAS and recurrent, unexplained congestive heart failure or sudden, unexplained pulmonary edema

Patients with hemodynamically significant RAS and unstable angina

$\mathrm{IIa} / \mathrm{B}$

Renal stent placement is indicated for ostial atherosclerotic RAS lesions that meet the clinical criteria for intervention

$A T S-R V H$ atherosclerotic renovascular hypertension, $R A S$ renal artery stenosis, $H T$ hypertension

On the whole, PPGLs are rare, as they comprise less than $0.2-0.6 \%$ of the patients with HT. Due to the huge variation of clinical presentation, PPGLs have been defined as 'the great simulators' as symptoms can range from none to many. Symptoms are usually due to a mass effect and/ or derive from catecholamines excess. Paroxysmal or sustained high BP is the most common sign of PPGLs and involves up to $80 \%$ of patients (Table 6). In syndromic cases, the concurrence of physical signs (see later) should suggest the diagnosis (Table 6) [36-38]. However, PPGLs occurring in the head and neck district are usually parasympathetic, and therefore do not secrete catecholamines. Hence, these patients usually present to the otolaryngologist and/or to the vascular surgeon for the detection of cervical masses or nodules [37].

\subsection{Screening and Diagnostic Tests}

Syndromic PPGLs, including neurofibromatosis type 1, multiple endocrine neoplasia type 2, von Hippel-Lindau syndrome, renal cell carcinoma with SDHB mutation, Carney triad, and Carney-Stratakis syndrome, are rare and characterized by typical clinical phenotypes and associated comorbidities, which render the clinical suspicion quite obvious. The work-up for HT patients with non-syndromic and syndromic PPGLs is shown in Fig. 3. Biochemical tests for suspected cases include measurements of urinary and/or plasma free normetanephrines and metanephrines that are the most accurate tests to detect or exclude PPGLs. Detection of plasma metanephrines must be performed under standardized conditions such as stress-free conditions (e.g. after rest in the supine position), and with positioning an indwell cannula to avoid the pain of venipuncture, to limit false-positive results. The measurement of conjugated metanephrines in 24-h urine has been demonstrated to cause
Table 6 Most frequent clinical manifestations of PPGLs and their distribution Adapted from Mannelli $M$, et al. Pheochromocytoma in Italy: A multicentric retrospective study. Eur J Endocrinol. 1999;141:619-24 [37]

\begin{tabular}{ll}
\hline Signs and symptoms & \\
Sustained or paroxysmal HT & $80-90 \%$ \\
Palpitations and tachycardia & $58 \%$ \\
Headaches & $52 \%$ \\
Sweating attacks & $49 \%$ \\
Anxiety and panic attacks & $35 \%$ \\
Tremors & $26 \%$ \\
Nausea & $22 \%$ \\
Dyspnea & $17 \%$ \\
Abdominal pain & $16 \%$ \\
Vertigo & $16 \%$ \\
Parasthesiae & $12 \%$ \\
Chest pain & $12 \%$ \\
Weakness & $11 \%$ \\
Diarrhea/constipation & $5 \%$ \\
Fever & $2 \%$ \\
Other suggestive conditions & \\
Paradoxical response to some precipitating drugs & \\
Dilated cardiomyopathy & \\
Erythrocytosis, hyperglycemia, hypercalcemia & \\
Adrenal incidentaloma, with or without HT & \\
Hereditary predisposition or syndromic features suggesting heredi- \\
tary PPGLs
\end{tabular}

$H T$ hypertension

false positive test results, and thus free metanephrines should be preferred [38]. Imaging is recommended when the screening is positive (e.g. magnetic resonance imaging-MRI or CT); due to their high vascularization PPGLs usually show up as hyperintense lesions on T2-weighed MRI. 
In all patients with sporadic (non-familial) PPGLs genetic testing is recommended for the following reasons: (1) about one-third of these patients have germline mutations; (2) some of the mutations, for example, those of succinate dehydrogenase subunit B (SDHB), are associated to a higher risk of malignant/metastatic disease; (3) a germline mutation in the proband, unless occurring de novo, indicates a familial form, which can allow earlier diagnosis and treatment of PPGLs in the relatives [36].

\subsection{Treatment}

The gold-standard therapy for PPGLs is surgery for solitary or multiple tumors clustered in one area (Fig. 3) [36, 38].

Diagnostic algorithm for identification of PPGLs
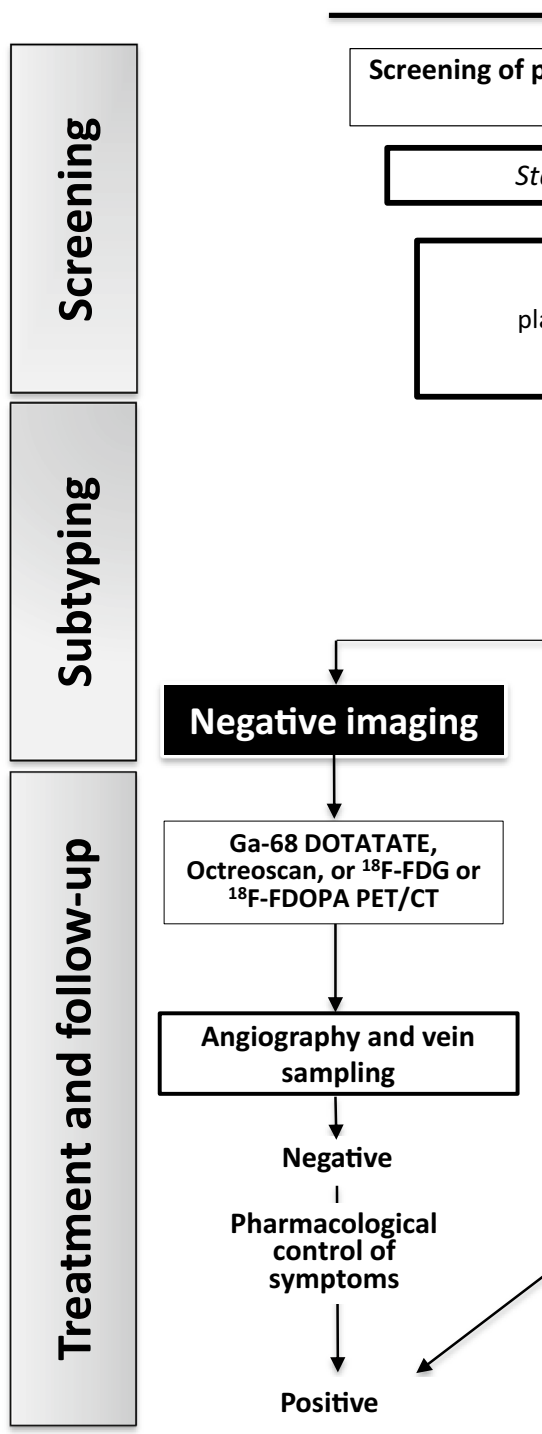

Positive
Biochemical testing*:

plasma or urinary free metanephrine and normetanephrine
Borderline: repeat sampling or consider clonidine suppression test**

maging: MRI or CT
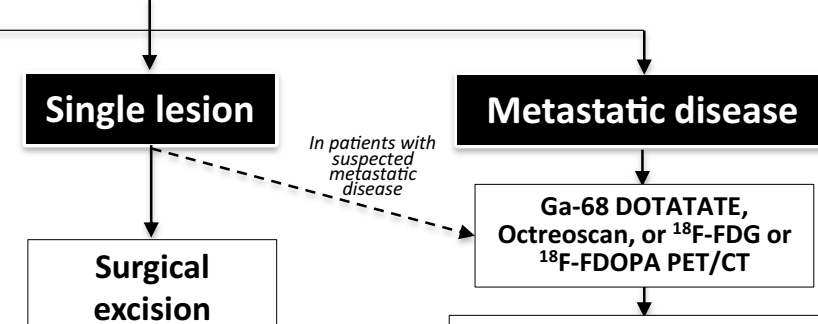

Repeat biochemical tests (about 6 weeks after surgery)

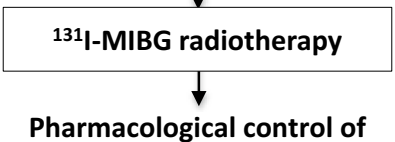

Pharmacological control of symptoms

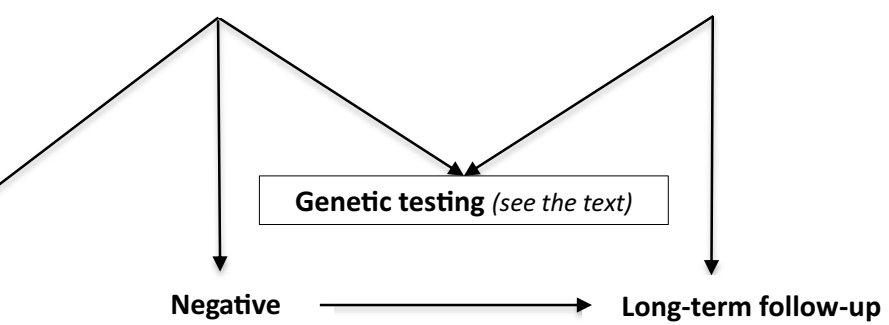

Fig. 3. A schematic algorithm suggested for diagnosis and treatment of hypertensive patients with suspected of pheochromocytoma and paraganglioma. CT has been suggested as the first-choice imaging modality because of its excellent spatial resolution for thorax, abdomen, and pelvis. MRI is recommended in patients with metastatic PPGLs, for detection of skull base and neck paragangliomas. *Biochemical screening should be performed after withdrawing of interfering drugs and substances, including acetaminophen, labetalol, sotalol, $\alpha$-methyldopa, tricyclic antidepressants, MAO-inhibitors, sympathomimetics, cocaine. **A quarter of patients with PPGLs show borderline biochemical results, likely due to inappropriate sampling. If results remain elevated after repeating the measurement, the clonidine suppression test with detecting of plasma normetanephrine can be used. This test has been claimed to have a $100 \%$ diagnostic specificity with a $97 \%$ sensitivity; however, it has not been validated in prospective studies. $H T$ hypertension, $C T$ computed tomography, $M R I$ magnetic resonance imaging, $M I B G$ metaiodobenzylguanidine, ${ }^{18} F-F D G \quad[18 \mathrm{~F}]$-fluoro-fluorodeoxyglucose, ${ }^{18} F$-FDOPA 6-[18F]L-fluoro-L-3,4-dihydroxyphenylalanine, PET positron-emission tomography 
Patients with hormonally functional PPGLs should undergo preoperative $\alpha 1$-blockade, followed by $\beta$-blockade and volume expansion to prevent perioperative $\mathrm{CV}$ complications. Antihypertensive treatment must include $\beta 1$-blockers, as doxazosin or terazosin. B-blockers can be used to controlled tachycardia and BP values, but only after $\alpha 1$-blockade. Likely because of $\alpha 1$-mediated vasoconstriction [5] PPGLs patients have a relative hypovolemia, i.e. a redistribution of blood volume from the periphery to the cardiopulmonary district. Hence, once the diagnosis has been made, before surgery and anesthesia, it is fundamental to correct this hypovolemia to avoid prominent hemodynamic instability.

Malignant forms are generally treated by meta-I-benzyl guanidine (MIBG) (for patients with metastatic disease who are MIBG positive) and/or chemo- or radiotherapy.

\section{Cushing's Syndrome}

Keynote
ACTH-dependent or -independent hypercortisolism is a rare cause of SH but, in these patients, the BP control is often difficult to achieve when the surgical removal of cortisol-producing tumors is not performed.
Excessive autonomous production of cortisol is the hallmark of Cushing's syndrome (CS) but accounts for less than $1 \%$ of endocrine causes of HT. However, high BP is reported in more than $80 \%$ of adults affected by CS [7].

\subsection{Screening and Diagnostic Tests}

On history, excessive use of exogenous glucocorticoid leading to iatrogenic CS must be ruled out before considering screening tests, which are indicated in the following categories of hypertensives: (1) patients with unusual features, for example, osteoporosis at a young age; (2) patients with suggestive signs and symptoms (Table 7); (3) adrenal incidentaloma compatible with adenoma [39]. The initial testing includes repeated (at least twice) measurements of 24-h urine free cortisol, late-night salivary cortisol, and 1-mg overnight dexamethasone suppression test. For the 1-mg overnight dexamethasone suppression test, a normal response is a serum cortisol less than $1.8 \mu \mathrm{g} / \mathrm{dL}$; when values are between 1.8 and $5 \mu \mathrm{g} / \mathrm{dL}$ subclinical CS should be considered. The absence of cortisol suppression after dexamethasone (serum cortisol higher than $5 \mu \mathrm{g} / \mathrm{dL}$ or $>140 \mathrm{nmol} / \mathrm{L}$ ) indicates a CS diagnosis. Once a diagnosis of CS has been made the next step is to distinguish between ACTH-dependent CS (that accounts for $80-85 \%$ of cases), which show normal or increased plasma ACTH values and are due to pituitary or ectopic ACTH-secreting tumors, and the less common ACTH-independent CS [40], in which ACTH is low. Uncertainties can be resolved by the CRH stimulation test as ACTH-independent cases show persistently suppressed ACTH values. Patients with ACTHdependent CS should be evaluated in specialized tertiary referred centers by gadolinium-enhanced pituitary MRI, followed, when clinical, biochemical or radiological studies are discordant, by bilateral inferior petrosal sinus sampling. If ACTH is suppressed, abdominal CT scan or MRI should be done to identify the adrenal mass ( $90 \%$ are unilateral adrenal tumors) or hyperplasia (unilateral or bilateral) [41].

\subsection{Treatment}

Controlling cortisol hypersecretion by surgery or by cortisol lowering drugs or glucocorticoid receptor antagonists, can effectively lower BP in most hypertensive CS patients and normalize it in $\sim 50 \%$ of cases [42]. Definitive therapy for CS is surgical excision of ACTH- or cortisol-producing tumor with a post-operative cure rate of $65-90 \%$. In patients with contraindications to surgery, or with ectopic disease and persistent hypercortisolism, BP values are often difficult to control, and the most frequent causes of death are the $\mathrm{CV}$

Table 7 Signs and symptoms associated with Cushing's syndrome and their prevalence Adapted from Nieman LK, et al. The diagnosis of Cushing's syndrome: An endocrine society clinical practice guideline. J Clin Endocrinol Metab. 2008;93:1526-40 [39]

\begin{tabular}{ll}
\hline Decreased libido & $91-100 \%$ \\
Facial rounding (“moon faces") & \\
Obesity & \\
Impaired glucose tolerance/diabetes & $71-90 \%$ \\
Menstrual changes & \\
Hirsutism & \\
Striae rubre & $51-70 \%$ \\
Muscle weakness & \\
Osteopenia/osteoporosis/fractures & \\
Psychiatric disturbances (especially lethargy, depression) & \\
Atherosclerosis & \\
Easy bruising & $21-50 \%$ \\
Impaired wound healing & \\
Headaches & \\
Backache & \\
Recurrent infections & \\
Edema & \\
Hypokalemic alkalosis & \\
Acne & \\
Hair loss &
\end{tabular}


complications. In these patients and in those with persistent high BP after surgery, an association of multiple antihypertensive drugs, including renin-angiotensin-aldosterone system (RAAS) modulators (i.e. ACE-inhibitors, angiotensin II receptor blockers-ARBs, and MRAs), is usually necessary [41].

\section{Obstructive Sleep Apnea}

\section{Keynote}

\section{OSA is a frequent cause of $\mathrm{SH}$ and 'difficult-to-treat' HT. Patients with obesity, snoring, upper airway abnormalities, excessive daytime sleepiness, reduced sleep-related quality of life should be screened for OSA The effect of PAP on BP is still controversial but, if associated with sleep hygiene and specific antihypertensive drugs, it can ameliorate BP control with the largest effect on nocturnal BP.}

Obstructive sleep apnea (OSA) is an independent risk factor for HT and cardiovascular diseases [43] and is common in adults, particularly in patients with difficult-to-treat HT [44]. Its identification as the underlying cause of HT, followed by specific treatment, can render high BP responsive to treatment [44]. Fragmented, albeit rather consistent, evidence suggested that OSA can coexist with PA and that target treatment of the latter can ameliorate OSA [45]. However, results of a recent multicenter study seem to have challenged this view [46]; therefore, whether OSA is a presenting sign of PA or vice versa, remains somewhat controversial. Nonetheless, there are no doubts that patients with difficult-to-treat HT should be screened for either condition because identification of one or both can allow to better control their high BP and improve their quality of life.

\subsection{Screening and Diagnostic Tests}

Well recognized signs and symptoms (Table 8) should lead to screen hypertensive patients for OSA [47-49]. In-laboratory full-night polysomnography is the diagnostic gold standard for OSA patients [48, 49]. It allows to identify the severity of disease (i.e. through apnea/hypopnea indexAHI-measurement), the associated sleep disorders, and the response to treatment. When unfeasible, the home sleep apnea testing can be used, particularly for uncomplicated adults with suspect of OSA (Fig. 4).

\subsection{Treatment}

The proper work-up of OSA patients varies according to individual features. The first steps are the lifestyle changes and sleep hygiene (Fig. 4) (i.e. avoiding alcohol, caffeine or stimulants of wakefulness before sleep; increased physical activity during the day and obesity control; avoiding naps at unusual hours; discontinuation of hypnotic drugs). An ear-nose-throat (ENT) evaluation is recommended for OSA subjects with suspected upper airway abnormalities. The ENT specialist could also perform drug-induced sleep endoscopy examination that allows an accurate identification and correction of the obstruction [50]. In moderate-to-severe OSA (i.e. AHI $\geq 15$ events per hour), especially in patients with symptoms of excessive daytime sleepiness, reduced

Table 8 Clinical presentation of OSA

\begin{tabular}{|c|c|}
\hline Signs and symptoms & Clinical examination \\
\hline $\begin{array}{l}\text { Snoring during sleep, frequent nycturia, poor quality of sleep, night-time } \\
\text { sweating, waking up gasping or choking } \\
\text { Decreased libido } \\
\text { Excessive daytime sleepiness } \\
\text { Morning dry mouth } \\
\text { Daytime headache, impaired attention and memory during work activities } \\
\text { Motor vehicle accidents } \\
\text { High-risk patients include also those with current and/or past history of } \\
\text { arrhythmias, pulmonary HT, diabetes type } 2 \text { mellitus, coronary disease, } \\
\text { and 'difficult-to-treat' HT } \\
\text { 24-h ABPM characterized by a non-dipping profile and elevated BP vari- } \\
\text { ability indices }\end{array}$ & $\begin{array}{l}\text { Upper airway abnormalities (e.g. Mallampati score } \geq 3 \text { ) } \\
\text { Neck and waist circumference (e.g. neck circumference }>43 \mathrm{~cm} \text { in } \\
\text { males and }>40 \mathrm{~cm} \text { in females) } \\
\text { BMI (e.g. } \geq 30 \mathrm{~kg} / \mathrm{m}^{2} \text { ) }\end{array}$ \\
\hline
\end{tabular}

The criteria developed by the American Academy of Sleep Medicine (AASM) are a combination of at least 5 obstructive breathing episodes per hour during sleep and at least one of the following criteria: (a) excessive daytime sleepiness that is not better explained by other factors; (b) two or more of the following symptoms not explained by other factors: choking or gasping during sleep, recurrent awakenings from sleep, unrefreshing sleep, daytime fatigue, and impaired concentration [48]

$O S A$ obstructive sleep apnea, $H T$ hypertension, $A B P M$ ambulatory blood pressure monitoring, $B M I$ body mass index 
sleep-related quality of life, and/or hypertension positive airway pressure (PAP) therapy, including continuous, selftitrated systems, and bilevel (as a second-level option), is the recommended treatment [51], which allows to maintain the upper airway patency and lower sympathetic [52] and RAAS activation [53, 54], by improving oxyhemoglobin saturation. PAP treatment improves signs and symptoms of OSA, and lowers BP values, more strongly in OSA patients with resistant hypertension [51, 55-58]. However, its effectiveness on BP and cardiovascular profile depends on patients' adherence to treatment, which is often poor. Interestingly, recent data demonstrated a clinically significant improvement in
PAP adherence and thereby improve symptom control in the treatment of OSA in adults with the use of telemonitoring intervention [51].

Only a few studies have evaluated the effects of antihypertensive agents on OSA. Their results were variable and statistical power was usually poor [47]. Growing evidence supports the role of high levels of plasma aldosterone in OSA that appear to contribute to poor control of BP values in these patients through peri-pharyngeal fluid retention [59]. By reducing parapharyngeal edema and upper airway obstruction, diuretics (i.e. MRAs) improve OSA severity and BP control $[45,60,61]$. Further studies are necessary

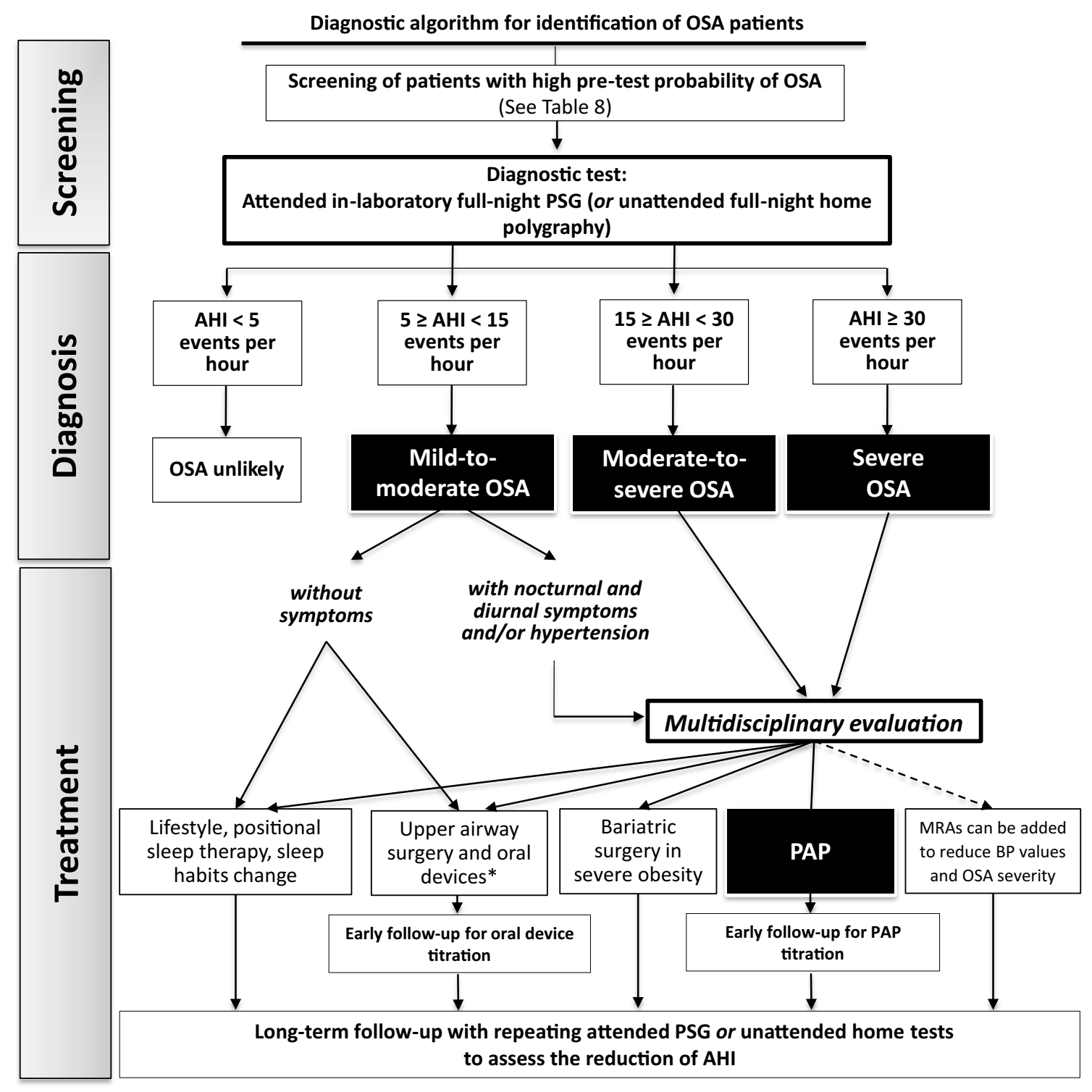

Fig. 4 Schematic algorithm summarizing the steps for recognition of obstructive sleep apnea and its diagnostic and therapeutic workup. *Upper airway surgery and oral appliances are indicated only for specific cases with objective upper airways abnormalities. OSA obstructive sleep apnea, $P S G$ polysomnography, $A H I$ apnea/hypopnea index, $P A P$ positive airway pressure, $M R A s$ mineralocorticoid receptor antagonists 
to confirm this suggestion. A promising therapeutic strategy is the electrical stimulation of upper airway via hypoglossal nerve $[62,63]$, but data on its effect on BP are still preliminary.

\section{Conclusions}

The detection of SH can be simplified and made cost-effective by estimating the patient's prior (pre-test) probability of the disease, which can be established by knowing the prevalence of the most common forms and by following few rules, as herein presented. Once a form of SH has been detected, knowledge of the underlying pathophysiology warrants a more rational and more effective treatment, which can allow to achieve long-term cure of arterial hypertension or a better control of the high BP values when cure is not accomplished. These outcomes are rewarding for the doctor, but even more so for the patient, who will avoid the complications of life-long exposure to high BP values, will enjoy a better quality of life, as convincingly documented in PA and OSA, and ultimately will no longer be life-long labelled as 'patient'.

\section{Declarations}

Funding Open access funding provided by Università degli Studi di Padova within the CRUI-CARE Agreement. This study was funded by: Gian Paolo Rossi: European Cooperation in Science and Technology (Grant nos. ADMIRE BM1301, ENSAT-HT 633983), Società Italiana dell'Ipertensione Arteriosa, FORICA (The Foundation for advanced Research In Hypertension and Cardiovascular diseases). The funders had no role in study design, data collection and interpretation, or the decision to submit the work for publication.

Conflict of interest Authors do not have any conflict of interest.

Ethical approval This article does not contain any studies with human participants performed by any of the authors.

Consent to participate Not applicable.

Consent for publication Not applicable.

Code availability statements Not applicable.

Open Access This article is licensed under a Creative Commons Attribution-NonCommercial 4.0 International License, which permits any non-commercial use, sharing, adaptation, distribution and reproduction in any medium or format, as long as you give appropriate credit to the original author(s) and the source, provide a link to the Creative Commons licence, and indicate if changes were made. The images or other third party material in this article are included in the article's Creative Commons licence, unless indicated otherwise in a credit line to the material. If material is not included in the article's Creative Commons licence and your intended use is not permitted by statutory regulation or exceeds the permitted use, you will need to obtain permission directly from the copyright holder. To view a copy of this licence, visit http://creativecommons.org/licenses/by-nc/4.0/.

\section{References}

1. Williams B, Mancia G, Spiering W, Agabiti Rosei E, Azizi M, Burnier M, et al. 2018 ESC/ESH guidelines for the management of arterial hypertension. Eur Heart J. 2018;39:3021-104.

2. Chiong JR, Aronow WS, Khan IA, Nair CK, Vijayaraghavan K, Dart RA, et al. Secondary hypertension: current diagnosis and treatment. Int J Cardiol. 2008;124:6-21.

3. Azizi M, Sapoval M, Gosse P, Monge M, Bobrie G, Delsart P, et al. Optimum and stepped care standardised antihypertensive treatment with or without renal denervation for resistant hypertension (DENERHTN): a multicentre, open-label, randomised controlled trial. Lancet. 2015;385:1957-65.

4. Rossi GP, Rossitto G, Amar L, Azizi M, Riester A, Reincke M, et al. Prevalence and outcome of drug-resistant hypertension in primary aldosteronism patients undergoing adrenal vein sampling. Eur J Prev Cardiol. 2020. (In press).

5. Rossi GP, Seccia TM, Pessina AC. Secondary hypertension: the ways of management. Curr Vasc Pharmacol. 2010;8:753-68.

6. Hirsch JS, Hong S. The demystification of secondary hypertension: diagnostic strategies and treatment algorithms. Curr Treat Options Cardiovasc Med. 2019;21:90.

7. Rimoldi SF, Scherrer U, Messerli FH. Secondary arterial hypertension: when, who, and how to screen? Eur Heart J. 2014;35:1245-54.

8. Mulatero P, Monticone S, Deinum J, Amar L, Prejbisz A, Zennaro $\mathrm{M}-\mathrm{C}$, et al. Genetics, prevalence, screening and confirmation of primary aldosteronism. J Hypertens. 2020. (Online ahead of print).

9. Rossi GP. Primary aldosteronism: JACC state-of-the-art review. J Am Coll Cardiol. 2019;74:2799-811.

10. Monticone S, Burrello J, Tizzani D, Bertello C, Viola A, Buffolo $\mathrm{F}$, et al. Prevalence and clinical manifestations of primary aldosteronism encountered in primary care practice. J Am Coll Cardiol. 2017;69:1811-20.

11. Rossi GP, Bernini G, Caliumi C, Desideri G, Fabris B, Ferri C, et al. A prospective study of the prevalence of primary aldosteronism in 1125 hypertensive patients. J Am Coll Cardiol. 2006; 48:2293-300

12. Calhoun DA, Nishizaka MK, Zaman MA, Thakkar RB, Weissmann P. Hyperaldosteronism among black and white subjects with resistant hypertension. Hypertension. 2002;40:892-6.

13. Douma S, Petidis K, Doumas M, Papaefthimiou P, Triantafyllou A, Kartali N, et al. Prevalence of primary hyperaldosteronism in resistant hypertension: a retrospective observational study. Lancet. 2008;372:2022.

14. Omata K, Satoh F, Morimoto R, Ito S, Yamazaki Y, Nakamura Y, et al. Cellular and genetic causes of idiopathic hyperaldosteronism. Hypertension. 2018;72:874-80.

15. Rossitto G, Amar L, Azizi M, Riester A, Reincke M, Degenhart $\mathrm{C}$, et al. Subtyping of primary aldosteronism in the AVIS-2 study: assessment of selectivity and lateralization. J Clin Endocrinol Metab. 2020;105:017.

16. Seccia TM, Fassina A, Nussdorfer GG, Pessina AC, Rossi GP. Aldosterone-producing adrenocortical carcinoma: an unusual cause of Conn's syndrome with an ominous clinical course. Endocr Relat Cancer. 2005;12:149-59.

17. Lenzini L, Prisco S, Caroccia B, Rossi GP. Saga of familial hyperaldosteronism yet a new channel. Hypertension. 2018;71:1010-4. 
18. Hiramatsu K, Yamada T, Yukimura Y, Komiya I, Ichikawa K, Ishihara M, et al. A screening test to identify aldosterone-producing adenoma by measuring plasma renin activity: results in hypertensive patients. Arch Intern Med. 1981;141:1589-93.

19. Rossi GP, Bisogni V. A useful tool to improve the case detection rate of primary aldosteronism: the aldosterone-renin ratio (ARR)App. J Hypertens. 2016;34:1019-21.

20. Ahmed AH, Gordon RD, Ward G, Wolley M, McWhinney $\mathrm{BC}$, Ungerer JP, et al. Effect of moxonidine on the aldosterone/ renin ratio in healthy male volunteers. J Clin Endocrinol Metab. 2017;102:2039-43.

21. Rossi GP, Ceolotto G, Rossitto G, Maiolino G, Cesari M, Seccia TM. Effects of mineralocorticoid and AT1 receptor antagonism on the aldosterone-renin ratio in primary aldosteronism-the EMIRA study. J Clin Endocrinol Metab. 2020;105:dgaa080.

22. Nanba AT, Wannachalee T, Shields JJ, Byrd JB, Rainey WE, Auchus RJ, et al. Adrenal vein sampling lateralization despite mineralocorticoid receptor antagonists exposure in primary aldosteronism. J Clin Endocrinol Metab. 2018;104:487-92.

23. Haase M, Riester A, Kröpil P, Hahner S, Degenhart C, Willenberg HS, et al. Outcome of adrenal vein sampling performed during concurrent mineralocorticoid receptor antagonist therapy. J Clin Endocrinol Metab. 2014;99:4397-402.

24. Byrd JB, Turcu AF, Auchus RJ. Primary aldosteronism: practical approach to diagnosis and management. Circulation. 2018;138:823-35.

25. Bossuyt PM, Reitsma JB, Bruns DE, Gatsonis CA, Glasziou PP, Irwig LM, et al. Toward complete and accurate reporting of studies of diagnostic accuracy: the STARD initiative. Am J Clin Pathol. 2003;119:18-22.

26. Maiolino G, Rossitto G, Bisogni V, Cesari M, Seccia TM, Plebani $\mathrm{M}$, et al. Quantitative value of aldosterone-renin ratio for detection of aldosterone-producing adenoma: the Aldosterone-Renin Ratio for Primary Aldosteronism (AQUARR) study. J Am Heart Assoc. 2017;6:e005574.

27. Funder JW, Carey RM, Mantero F, Murad MH, Reincke M, Shibata $\mathrm{H}$, et al. The management of primary aldosteronism: Case detection, diagnosis, and treatment: An endocrine society clinical practice guideline. J Clin Endocrinol Metab. 2016;101:1889-916.

28. Rossi GP, Bisogni V, Bacca AV, Belfiore A, Cesari M, Concistrè A, et al. The 2020 Italian Society of Arterial Hypertension (SIIA) practical guidelines for the management of primary aldosteronism. Int J Cardiol Hypertens. 2020;5:1000292.

29. Rossi GP, Rossitto G, Amar L, Azizi M, Riester A, Reincke M, et al. Clinical outcomes of 1625 patients with primary aldosteronism subtyped with adrenal vein sampling. Hypertension. 2019;74:800-8.

30. Hundemer GL, Curhan GC, Yozamp N, Wang M, Vaidya A. Cardiometabolic outcomes and mortality in medically treated primary aldosteronism: a retrospective cohort study. Lancet Diabetes Endocrinol. 2018;6:51-9.

31. Gornik HL, Persu A, Adlam D, Aparicio LS, Azizi M, Boulanger $\mathrm{M}$, et al. First International Consensus on the diagnosis and management of fibromuscular dysplasia. Vasc Med (United Kingdom). 2019;24:164-89.

32. Rossi GP, Pavan E, Chiesura-Corona M, Bader M, Paganini G, Cesari M, et al. Renovascular hypertension with low-to-normal plasma renin: clinical and angiographic features. Clin Sci. 1997;93:435-43.

33. Hirsch AT, Haskal ZJ, Hertzer NR, Bakal CW, Creager MA, Halperin JL, et al. ACC/AHA 2005 guidelines for the management of patients with peripheral arterial disease (lower extremity, renal, mesenteric, and abdominal aortic): a collaborative report from the American Association for Vascular Surgery/Society for Vascular Surgery. J Am Coll Cardiol. 2006;47:1239-312.
34. Prince M, Tafur JD, White CJ. When and how should we revascularize patients with atherosclerotic renal artery stenosis? JACC Cardiovasc Interv. 2019;12:505-17.

35. Bailey SR, Beckman JA, Dao TD, Misra S, Sobieszczyk PS, White CJ, et al. ACC/AHA/SCAI/SIR/SVM 2018 appropriate use criteria for peripheral artery intervention: a report of the American College of Cardiology Appropriate Use Criteria Task Force, American Heart Association, Society for Cardiovascular Angiography and Interventions. J Am Coll Cardiol. 2019;73:214-37.

36. Lenders JWM, Duh QY, Eisenhofer G, Gimenez-Roqueplo AP, Grebe SKG, Murad MH, et al. Pheochromocytoma and paraganglioma: an endocrine society clinical practice guideline. J Clin Endocrinol Metab. 2014;99:1915-42.

37. Mannelli M, Ianni L, Cilotti A, Conti A. Pheochromocytoma in Italy: a multicentric retrospective study. Eur J Endocrinol. 1999;141:619-24.

38. Lenders JWM, Kerstens MN, Amar L, Prejbisz A, Robledo M, Taieb D, et al. Genetics, diagnosis, management and future directions of research of pheochromocytoma and paraganglioma: a position statement and consensus of the Working Group on Endocrine Hypertension of the European Society of Hypertension. J Hypertens. 2020;38:1443-56.

39. Nieman LK, Biller BMK, Findling JW, Newell-Price J, Savage MO, Stewart PM, et al. The diagnosis of Cushing's syndrome: an endocrine society clinical practice guideline. J Clin Endocrinol Metab. 2008;93:1526-40.

40. Sharma ST, Nieman LK, Feelders RA. Cushing's syndrome: Epidemiology and developments in disease management. Clin Epidemiol. 2015;7:281-93.

41. Singh Y, Menon A, Kotwal N. Endocrine hypertension-Cushing's syndrome. Indian J Endocrinol Metab. 2011;15:S313-6.

42. Barbot M, Ceccato F, Scaroni C. The pathophysiology and treatment of hypertension in patients with Cushing's syndrome. Front Endocrinol (Lausanne). 2019;10:321.

43. Peppard PE, Young T, Palta M, Skatrud J. Prospective study of the association between sleep-disordered breathing and hypertension. N Engl J Med. 2000;342:1378-84.

44. Pedrosa RP, Drager LF, De Paula LKG, Amaro ACS, Bortolotto LA, Lorenzi-Filho G. Effects of OSA treatment on BP in patients with resistant hypertension: a randomized trial. Chest. 2013;144:1487-94.

45. Prejbisz A, Kołodziejczyk-Kruk S, Lenders JWM, Januszewicz A. Primary aldosteronism and obstructive sleep apnea: is this a bidirectional relationship? Horm Metab Res. 2017;49:969-76.

46. Buffolo F, Li Q, Monticone S, Heinrich DA, Mattei A, Pieroni J, et al. Primary aldosteronism and obstructive sleep apnea a crosssectional multi-ethnic study. Hypertension. 2019;74:1532-40.

47. Parati G, Lombardi C, Hedner J, Bonsignore MR, Grote L, Tkacova R, et al. Recommendations for the management of patients with obstructive sleep apnea and hypertension. Eur Respir J. 2013;41:523-38.

48. Epstein LJ, Kristo D, Strollo PJ, Friedman N, Malhotra A, Patil $\mathrm{SP}$, et al. Clinical guideline for the evaluation, management and long-term care of obstructive sleep apnea in adults. J Clin Sleep Med. 2009;5:263-76.

49. Kapur VK, Auckley DH, Chowdhuri S, Kuhlmann DC, Mehra $\mathrm{R}$, Ramar K, et al. Clinical practice guideline for diagnostic testing for adult obstructive sleep apnea: an American academy of sleep medicine clinical practice guideline. J Clin Sleep Med. 2017;13:479-504.

50. De Vito A, Carrasco Llatas M, Ravesloot MJ, Kotecha B, De Vries N, Hamans E, et al. European position paper on druginduced sleep endoscopy: 2017 update. Clin Otolaryngol. 2018;43:1541-52.

51. Patil SP, Ayappa IA, Caples SM, John Kimoff R, Patel SR, Harrod CG. Treatment of adult obstructive sleep apnea with positive 
airway pressure: an American Academy of sleep medicine systematic review, meta-analysis, and GRADE assessment. J Clin Sleep Med. 2019;15:301-34.

52. Bisogni V, Pengo MF, Maiolino G, Rossi GP. The sympathetic nervous system and catechol amines metabolism in obstructive sleep apnea. J Thorac Dis. 2016;8:243-54.

53. Nicholl DDM, Hanly PJ, Poulin MJ, Handley GB, Hemmelgarn $\mathrm{BR}$, Sola DY, et al. Evaluation of continuous positive airway pressure therapy on renin-angiotensin system activity in obstructive sleep apnea. Am J Respir Crit Care Med. 2014;190:572-80.

54. Haentjens P, Van Meerhaeghe A, Moscariello A, De Weerdt S, Poppe K, Dupont A, et al. The impact of continuous positive airway pressure on blood pressure in patients with obstructive sleep apnea syndrome: evidence from a meta-analysis of placebocontrolled randomized trials. Arch Intern Med. 2007;16:757-64.

55. Javaheri S, Barbe F, Campos-Rodriguez F, Dempsey JA, Khayat $\mathrm{R}$, Javaheri S, et al. Sleep apnea: types, mechanisms, and clinical cardiovascular consequences. J Am Coll Cardiol. 2017;69:841-58.

56. Bratton DJ, Stradling JR, Barbé F, Kohler M. Effect of CPAP on blood pressure in patients with minimally symptomatic obstructive sleep apnea: a meta-analysis using individual patient data from four randomised controlled trials. Thorax. 2014;69:1128-35.
57. Fava C, Dorigoni S, Dalle Vedove F, Danese E, Montagnana M, Guidi GC, et al. Effect of CPAP on blood pressure in patients with OSA/hypopnea: a systematic review and meta-analysis. Chest. 2014;145:762-71.

58. Bakker JP, Edwards BA, Gautam SP, Montesi SB, Durán-Cantolla $\mathrm{J}$, Barandiarán FA, et al. Blood pressure improvement with continuous positive airway pressure is independent of obstructive sleep apnea severity. J Clin Sleep Med. 2014;10:365-9.

59. Morimoto S, Ichihara A. Management of primary aldosteronism and mineralocorticoid receptor-associated hypertension. Hypertens Res. 2020;43:744-53.

60. Torres G, Sánchez-De-La-Torre M, Barbé F. Relationship between OSA and hypertension. Chest. 2015;148:824-32.

61. Gaddam K, Pimenta E, Thomas SJ, Cofield SS, Oparil S, Harding $\mathrm{SM}$, et al. Spironolactone reduces severity of obstructive sleep apnea in patients with resistant hypertension: a preliminary report. J Hum Hypertens. 2010;24:532-7.

62. Woodson BT, Strohl KP, Soose RJ, Gillespie MB, Maurer JT, de Vries N, et al. Upper airway stimulation for obstructive sleep apnea: 5-year outcomes. Otolaryngol Head Neck Surg (United States). 2018;159:194-202.

63. Pengo MF, Xiao S, Ratneswaran C, Reed K, Shah N, Chen T, et al. Randomised sham-controlled trial of transcutaneous electrical stimulation in obstructive sleep apnoea. Thorax. 2016;71:923-31. 